\title{
Genome-wide expression profiling of 8-chloroadenosine- and 8-chloro-cAMP-treated human neuroblastoma cells using radioactive human cDNA microarray
}

\author{
Gil Hong Park ${ }^{1}$, Jaegol Choe ${ }^{2}$, \\ Hyo-Jung Choo', Yun Gyu Park', \\ Jeongwon Sohn ${ }^{1}$, and Meyoung-kon Kim ${ }^{1,3}$ \\ ${ }^{1}$ Department of Biochemistry, College of Medicine, Korea University, \\ Seoul, 136-701, Korea \\ ${ }^{2}$ Department of Nuclear Medicine, College of Medicine, Korea Uni- \\ versity, Seoul, 136-701, Korea \\ ${ }^{3}$ Corresponding author: Tel, +82-2-920-6184; \\ Fax, +82-2-923-0480; E-mail, jerrykim @korea.ac.kr
}

Received 30 May , 2002

Abbreviations: 8-Cl-adenosine, 8-chloro-adenosine; 8-Cl-cAMP, 8chloro-cyclic adenosine 3,5-monophosphate; PKA, protein kinase $A$; RFXAP, regulatory factor $X$-associated protein; DCC, deleted in colorectal cancer; CDKs, cyclin-dependent kinases; $\mathrm{MHC}$, major histocompatibility complex; TGF- $\beta$, transforming growth factor- $\beta$; DYRK2, dual specificity tyrosine phosphorylated and regulated kinase 2

\begin{abstract}
Previous reports raised question as to whether 8chloro-cyclic adenosine 3,5-monophosphate (8-ClCAMP) is a prodrug for its metabolite, 8 -Cl-adenosine which exerts growth inhibition in a broad spectrum of cancer cells. The present study was carried out to clarify overall cellular affects of 8-Cl-cAMP and 8-Cl-adenosine on SK-N-DZ human neuroblastoma cells by systematically characterizing gene expression using radioactive human $\mathrm{CDNA}$ microarray. Microarray was prepared with PCR-amplified cDNA of 2,304 known genes spotted on nylon membranes, employing ${ }^{33} \mathrm{P}$-labeled $\mathrm{CDNAs}$ of SK-N-DZ cells as a probe. The expression levels of approximately 100 cDNAs, representing about $8 \%$ of the total DNA elements on the array, were altered in 8-Cl-adenosine- or 8-Cl-cAMP-treated cells, respectively. The genomewide expression of the two samples exhibited partial overlaps; different sets of up-regulated genes but the same set of down-regulated genes. 8-Cl-adenosine treatment up-regulated genes involved in differentiation and development (LIM protein, connexin 26 , neogenin, neurofilament triplet $L$ protein and p21 ${ }^{\text {WAF } 1 / C I P 1}$ ) and immune response such as natural killer cells protein 4, and down-regulated ones
\end{abstract}

involved in proliferation and transformation (transforming growth factor- $\beta$, DYRK2, urokinase-type plasminogen activator and proteins involved in transcription and translation) which were in close parallel with those by 8-Cl-cAMP. Our results indicated that the two drugs shared common genomic pathways for the down-regulation of certain genes, but used distinct pathways for the up-regulation of different gene clusters. Based on the findings, we suggest that the anti-cancer activity of 8-Cl-cAMP results at least in part through 8 -Cl-adenosine. Thus, the systematic use of DNA arrays can provide insight into the dynamic cellular pathways involved in anticancer activities of chemotherapeutics.

Keywords: 8-Cl-adenosine, 8-Cl-cAMP, anticancer activity, radioactive CDNA microarray, genome-wide expression

\section{Introduction}

8-Cl-adenosine, dephosphorylated metabolite of antineoplastic agent 8-Cl-cAMP has a growth-inhibitory effect, which is produced from $8-\mathrm{Cl}-\mathrm{cAMP}$ by the action of serum phosphodiesterase and 5-nucleotidase activity (Figure. 1) (Taylor et al., 1990; Lange-Carter et al., 1993; Halgren et al., 1998). 8-Cl-cAMP, a siteselective CAMP analogue, exhibits growth inhibition in a broad spectrum of cancer cell lines. However, its mechanism of action remains unelucidated. One possible mode of action is to induce cytotoxicity by acting as competitive inhibitor in biochemical pathway involving cAMP-dependent protein kinase [protein kinase A (PKA)] (Cho-Chung, 1989; Cho-Chung et al., 1995; Noguchi et al., 1998). PKA is a serine/threonine protein kinase that is activated by CAMP. Two isozymes of PKA, PKA-I and PKA-II, are distinguished by the association of type $R$ subunit $(R)$ or type $R$ subunit $(R)$ with common $C$ subunits, respectively. Four different $R$ subunits-Rla, Rlb, Rlla, and Rllb-have been identified (Taylor et al., 1990). Expression of the PKA Rla subunit is correlated with active cell growth and transformation, and increased in various human tumors and cell lines. Furthermore, overexpression of the PKA Rla subunit is correlated with malignancy and poor prognosis in cancer patients (Miller et al., 1993a; Miller et al., 1993b; Simpson et al., 1996; Miller et al., 1997). In contrast, a high level of Rb is correlated with growth arrest and differentiation (Cho- 


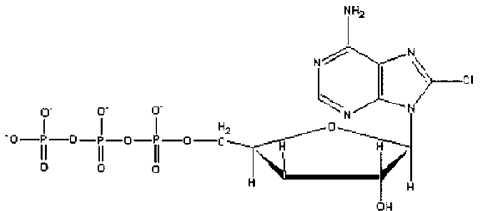

8-Cl-ATP
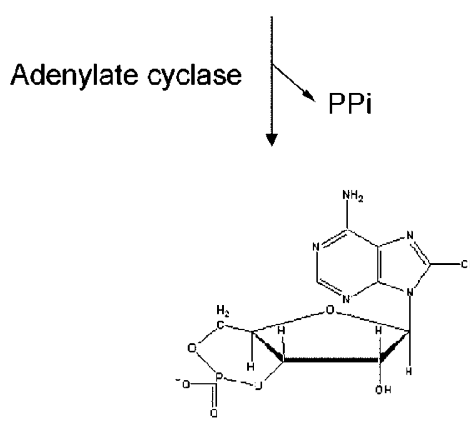

8-Cl-cAMP

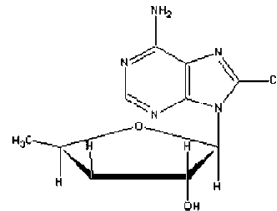

8-Cl-adenosine

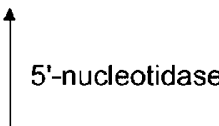

Cyclic nucleotide phosphodiesterase

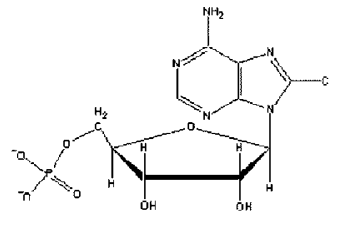

8-Cl-AMP

Figure 1. Metabolic conversion of 8-Cl-cAMP to 8-Cl-adenosine

Chung, 1990). Cancer cells treated with 8-Cl-cAMP showed a decrease of $R a$ and an increase of $R b$, leading to inhibition of cancer cell growth (Ally et al., 1988; Ciardiello et al., 1990; Rohlff et al., 1993).

The mechanism of 8-Cl-cAMP action is not yet clarified as to whether it is a prodrug for its metabolite, 8-Cl-adenosine. On the one side, 8-Cl-cAMP exerts its growth-inhibitory effect by binding to PKA in a competitive manner against cAMP (Rohlff et al., 1993; Noguchi et al., 1998) and on the other side, the effect of 8-Cl-cAMP is at least in part due to its metabolite 8-Cl-adenosine. Furthermore, the anticancer effect of 8-Cl-cAMP has been suggested to be independent of residual activity of PKA or concentration of cAMP (Lange-Carter et al., 1993; Cummings et al., 1996; Langefeld et al., 1997; Halgren et al., 1998; Carlson et al., 2001; Yin et al., 2001).

In order to evaluate the molecular portrait of anticancer actions of 8-Cl-adenosine versus 8-Cl-cAMP, we have selected human cDNA microarray comprised of 2,304 nonredundant human clones to examine whole spectrum of genes affected by both drugs. The microarray-based genomic survey is one of the highthroughput well known approaches, and has allowed parallel studies on expression patterns of thousands of genes (Schena et al., 1995; Duggan et al., 1999; Konu et al., 2001; Vawter et al., 2001). In the present study, we investigated genome-wide expression profiling under the treatment of 8 -Cl-adenosine or 8-Cl-cAMP as compared to untreated control. As a cancer cell model, SK-N-DZ human neuroblastoma cell line was chosen, because it has higher concentration of PKA than other types of cancer cells (Cho et al., 2000).

\section{Materials and Methods}

\section{Cell culture and RNA preparation}

SK-N-DZ cells (ATCC \#CRL-2149) grown in RPMI 1640 medium with $10 \%$ fetal bovine serum, 50 units $/ \mathrm{ml}$ penicillin, $500 \mu \mathrm{g} / \mathrm{ml}$ streptomycin, and $1 \mathrm{mM}$ glutamine (GIBCO) were seeded at $5 \times 10^{5}$ cells per dish at humidified atmosphere of $5 \% \mathrm{CO}_{2}$ at $37^{\circ} \mathrm{C}$. Cells were counted on a Coulter Counter, and were treated with $5 \mu \mathrm{M} 8-\mathrm{Cl}-$ adenosine (Biology Life Science Institute, Bremen, Germany) or 8-Cl-cAMP (National Cancer Institute, Drug Synthesis and Chemistry Branch, Bethesda, MD. USA) for $24 \mathrm{~h}$, respectively. Total RNA was prepared by using RNeasy Midi Kit (Qiagen, Chatsworth, CA, USA).

\section{Human cDNA microarray}

A human CDNA microarray was primarily derived from a commercially available master set of approximately 15,000 human verified-sequences (Research Genetics, Inc.). The 15,000 human cDNA clone set was sorted for a list of genes (2,304 elements) representing families such as differentiation, development, proliferation, transformation, cell cycle progression, immune response, transcription and translation factors, oncogenes, and molecules involved in cell growth and maintenance. PCR-amplified cDNAs were spotted on nylon membranes. The general methodology of arraying is based on the procedures of DeRisi et al. (1996).

\section{cDNA Radiolabeling}

Total RNAs prepared from SK-N-DZ cells treated with 8$\mathrm{Cl}$-adenosine or 8-Cl-cAMP and untreated control cells 
were used to synthesize ${ }^{33} \mathrm{P}$-labeled cDNAs by reverse transcription. Briefly, 3 10 $\mu \mathrm{g}$ RNA were labeled in a reverse transcription reaction containing $5 X$ first strand PCR buffer, $1 \mu \mathrm{g}$ of 24-mer poly dT primer, $4 \mu \mathrm{l}$ of 20 mM each dNTP excluding dCTP, $4 \mu \mathrm{l}$ of $0.1 \mathrm{M}$ DTT, 40 $\mathrm{U}$ of RNase inhibitor, $6 \mu \mathrm{l}$ of $3000 \mathrm{Ci} / \mathrm{mmol} \alpha^{33} \mathrm{P} \mathrm{dCTP}$ to a final volume of $40 \mu \mathrm{l}$. The mixture was heated at $65^{\circ} \mathrm{C}$ for $5 \mathrm{~min}$, followed by incubation at $42^{\circ} \mathrm{C}$ for $3 \mathrm{~min}$. Two $\mu$ l (specific activity: $200,000 \mathrm{U} / \mathrm{ml}$ ) of Superscript reverse transcriptase (Life Technologies) was then added and the samples were incubated for $30 \mathrm{~min}$ at $42^{\circ} \mathrm{C}$, followed by the addition of $2 \mu \mathrm{l}$ of Superscript reverse transcriptase and another $30 \mathrm{~min}$ of incubation. Five $\mu \mathrm{l}$ of $0.5 \mathrm{M}$ EDTA was added to chelate divalent cations. After the addition of $10 \mu \mathrm{l}$ of $0.1 \mathrm{M} \mathrm{NaOH}$, the samples were incubated at $65^{\circ} \mathrm{C}$ for $30 \mathrm{~min}$ to hydrolyze remaining RNA. Following the addition of $25 \mu \mathrm{l}$ of $1 \mathrm{M}$ Tris ( $\mathrm{pH}$ 8.0), the samples were purified using Bio-Rad 6 purification columns (Hercules, CA, USA). This resulted in $5 \times 10^{6}$ to $3 \times 10^{7} \mathrm{cpm}$ per reaction (Vawter et al., 2001).

\section{Hybridization and Scanning}

cDNA microarrays were pre-hybridized in hybridization buffer containing $4.0 \mathrm{ml}$ Microhyb (Research Genetics), $10 \mu \mathrm{l}$ of $10 \mu \mathrm{g} / \mathrm{ml}$ human Cot 1 DNA (Life Technologies), and $10 \mu \mathrm{l}$ of $8 \mathrm{mg} / \mathrm{ml}$ poly dA (Pharmacia, NJ). Both Cot 1 and poly $\mathrm{dA}$ were denatured at $95^{\circ} \mathrm{C}$ for $5 \mathrm{~min}$ prior to use. After $4 \mathrm{~h}$ of pre-hybridization at $42^{\circ} \mathrm{C}$, approximately $10^{7} \mathrm{cpm} / \mathrm{ml}$ of heat-denatured $\left(95^{\circ} \mathrm{C}, 5 \mathrm{~min}\right)$ probes were added and incubation was continued for $17 \mathrm{~h}$ at $42^{\circ} \mathrm{C}$. Hybridized arrays were washed three times in $2 \mathrm{X}$ SSC and $0.1 \%$ SDS for $15 \mathrm{~min}$ at room temperature. The microarrays were exposed to phosphorimager screens for 1-5 days, and the screens were then scanned in a FLA-8000 (Fuji Photo Film Co) at $50 \mu \mathrm{m}$ resolution (Vawter et al., 2001).

\section{Data analysis}

Microarray images were trimmed and rotated for further analysis using L-Processor (Fuji Photo Film Co). Gene expression of each microarrays was captured by the intensity of each spot produced by radioactive isotopes. Pixels per spot were counted by Arrayguage (Fuji Photo Film Co) and were exported to Microsoft Excel (Microsoft, Seattle, WA, USA). The data were normalized with $Z$ transformation to obtain $Z$ scores by subtracting each average of gene intensity and dividing with each standard deviation. Z scores provide each of 2,304 genes with the distance from the average intensity and were expressed in units of standard deviation. Thus, each $Z$ score provides flexibility to compare different sets of microarray experiments by adjusting differences in hybridization intensities.

Gene expression difference as compared to untreated control cells was calculated by comparing the $Z$ score differences ( $Z$ differences) among the same genes. This facilitates to compare each gene that had been up- or downregulated as compared to the control cells. $Z$ differences were calculated first by subtracting $Z$ scores of the control from each $Z$ score of the samples. These differences were normalized again to distribute their position by subtracting the average $Z$ difference and dividing with the standard deviation of the $Z$ differences. These distributions represent the $Z$ ratio value, and provide the efficiency for comparing each microarray experiment (Vawter et al., 2001).

Spotfire produced scatter plots of intensity values. (Spotfire, Inc., Cambridge, MA) (Tanaka et al., 2000). Cluster analysis was performed on Z-transformed microarray data by using two programs available as shareware from Michael Eisens laboratory (http:// rana.lbl.gov). Clustering of changes in gene expression was determined by using public domain Cluster based on pair wise complete-linkage cluster analysis (Eisen et al., 1998).

\section{Western analysis}

SK-N-DZ cells were seeded at a density of $1 \times 10^{6}$ cells/ $100-\mathrm{mm}$ plate and treated with $8-\mathrm{Cl}$-adenosine or $8-\mathrm{Cl}$ CAMP ( $5 \mu \mathrm{M}$ each) for 12 or $24 \mathrm{~h}$. Cells were washed twice with ice-cold PBS, lysed in buffer $(20 \mathrm{mM}$ Tris/ $\mathrm{HCl}$, $100 \mu \mathrm{M} \mathrm{NaCl}, 5 \mathrm{mM} \mathrm{MgCl}, 1 \% \mathrm{NP}-40,0.5 \%$ sodium deoxycholate, $100 \mu \mathrm{M}$ pepstatin, $100 \mu \mathrm{M}$ antipain, 100 $\mu \mathrm{M}$ chymostatin, $10 \mu \mathrm{g} / \mathrm{ml}$ leupeptin, $0.5 \mu \mathrm{M}$ phenylmethylsulfonyl fluoride, $5 \mathrm{mg} / \mathrm{ml}$ trypsin inhibitor, and $1 \mathrm{mM}$ benzamidine, $\mathrm{pH}$ 7.5), and placed on ice for $15 \mathrm{~min}$. Protein concentration was determined by the Bradford assay using the Bio-Rad protein assay kit (Bio-Rad). Cell extracts were subjected to SDS-PAGE, and Western analysis was performed according to the described method (Srivastava et al., 1999). Primary antibodies for P21 $1^{\text {WAF1/CIP1 }}$ (Cat. No. 33-7000) and human growth hormone-dependent insulin-like growth factor-binding protein (IGFBP), and FITC-labeled secondary antibody (Cat. No. 62-6511) were products of Zymed lab. (San Francisco, CA, USA).

\section{Results and Discussion}

\section{Microarray reproducibility}

To assess the reliability of microarray technique used, we calculated microarray reproducibility between duplicates. The duplicate genetic elements for each microarray resulted in two separate $Z$ normalizations and an average $Z$ score for each gene. The scatter plot for $Z$ scores in untreated control and 8-Cl-adenosine- or 8-Cl-cAMP-treated cells showed $R^{2}$ across duplicates of $0.81,0.83$, and 0.95 , respectively (Figure. 2). A perfect 

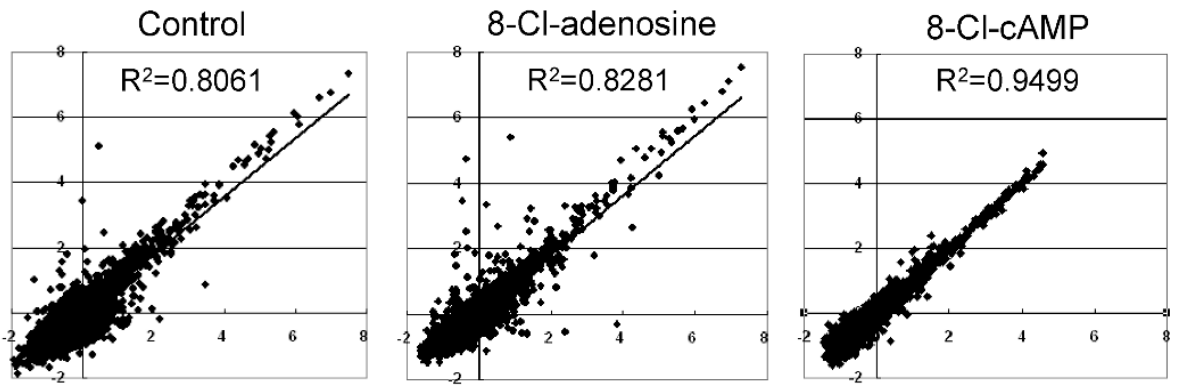

Figure 2. Microarray reproducibility. Each microarray contains two identical grids. Regression analysis of $Z$ scores from two independent samples of untreated control and 8-Cl-adenosine- or 8-Cl-CAMP-treated SK-N-DZ cells were performed. Z scores of individual genes from each member of duplicates were plotted, and the relationship between two samples was calculated to obtain $\mathrm{R}^{2}$. Based on $\mathrm{R}^{2}$, microarray hybridization patterns were found to be highly consistent between the samples. A perfect relationship between samples would be a slope of 1 .

relationship between duplicates would be a slope of 1 . The average coefficient of variation for duplicate $Z$ scores within each microarray was below $20 \%$ approximately, indicating a high reliability of our microarray data.

\section{Expression profiles between 8-Cl-adenosine- and 8- Cl-cAMP-treated SK-N-DZ cells}

The mechanism of 8-Cl-cAMP action has been controversial among some academics that begun more than a decade ago (Ally et al., 1988; Ciardiello et al., 1990; Rohlff et al., 1993). One of the possible mechanisms has been suggested to be through direct modulation of PKA activity and the other via its metabolite, 8-Cladenosine. In order to identify the genomic mechanism

Table 1. Expression profile of genes altered in SK-N-DZ cells treated with 8-Cl-adenosine or 8-Cl-cAMP

\begin{tabular}{|c|c|c|}
\hline \multirow{2}{*}{ Genes } & \multicolumn{2}{|c|}{ Fold change } \\
\hline & 8-Cl-adenosine & 8-Cl-cAMP \\
\hline Homo sapiens (clone s153) mRNA fragment & 7.82 & -0.44 \\
\hline H.sapiens mRNA for M130 antigen & 6.85 & -0.39 \\
\hline Human LIM protein MLP mRNA, complete cds & 5.54 & 0.32 \\
\hline Gap junction protein, beta 2, 26kD (connexin 26) & 5.43 & -0.22 \\
\hline Hexokinase 1 & 5.06 & -1.26 \\
\hline Prostate specific antigen & 4.54 & 0.98 \\
\hline Neurofilament triplet $L$ protein & 4.17 & 5.53 \\
\hline H.sapiens RFXAP mRNA & 3.96 & 0.17 \\
\hline Histidine ammonia-lyase & 3.74 & 1.24 \\
\hline Hepatoma transmembrane kinase & 3.54 & 0.45 \\
\hline Cyclin-dependent kinase inhibitor 1A (p21Waf1/Cip1) & 3.40 & 0.33 \\
\hline Homo sapiens clone 22 mRNA, alternative splice variant alpha & 3.28 & -0.64 \\
\hline Human mRNA for golgi antigen gcp372, complete cds & 3.03 & 0.27 \\
\hline Neogenin (chicken) homolog 1 & 3.02 & 2.32 \\
\hline Heterogeneous nuclear ribonucleoproteins $\mathrm{C} 1 / \mathrm{C} 2$ & 2.91 & -0.70 \\
\hline H.sapiens insulin-like growth factor binding protein 2 & 0.16 & 3.55 \\
\hline Vacuolar H+ ATPase proton channel subunit & -2.66 & -1.91 \\
\hline Urokinase-type plasminogen activator & -2.66 & -1.29 \\
\hline General transcription factor IIF, polypeptide 1 ( $74 \mathrm{kD}$ subunit) & -2.74 & -2.03 \\
\hline ERGIC-53 protein precursor & -2.75 & -1.46 \\
\hline Neutrophil gelatinase-associated lipocalin precursor & -2.76 & -2.69 \\
\hline Probable G protein-coupled receptor LCR1 homolog & -2.82 & -2.29 \\
\hline Human clone 23839 mRNA sequence & -2.90 & -1.33 \\
\hline Laminin B1 chain & -2.96 & -2.30 \\
\hline Transcription factor 12 (HTF4, helix-loop-helix transcription factors 4) & -3.03 & -2.47 \\
\hline Cartilage linking protein 1 & -3.08 & -3.06 \\
\hline Dihydropyrimidine dehydrogenase & -3.27 & -3.04 \\
\hline DYRK2 & -4.43 & -3.55 \\
\hline Carbonic anhydrase lib & -5.68 & -4.90 \\
\hline Human mRNA for stac, complete cds & -6.20 & -4.60 \\
\hline Human mRNA for TGF-beta superfamily protein, complete cds & -7.32 & -6.29 \\
\hline
\end{tabular}


specific for anticancer activity of 8-Cl-adenosine or 8-ClcAMP by using DNA microarray technology, three independent experiments were performed and a representative one was selected. The expression levels of $\approx 100 \mathrm{cDNA}$, representing $\approx 8 \%$ of the total DNA elements on the array, were found to be altered ( $\geq 2$-fold up-regulated or down-regulated as compared to untreated control) in 8-Cl-adenosine- and 8-Cl-cAMP-treated cells, respectively. The changes ranged from -7.3 fold to +7.8 fold in 8-Cl-adenosine-treated cells, and -6.29 fold to +8.1 fold in 8-Cl-cAMP-treated cells. There were 42 upregulated and 59 down-regulated genes in 8-Cladenosine-treated cells and 65 up-regulated and 41 down-regulated genes in 8-Cl-cAMP-treated cells.

Genes showing highly altered expression levels in treated cells were aligned in the order of the magnitude of altered expression in 8-Cl-adenosine-treated cells (Table 1). The expression profile of 8-Cl-adenosine- or 8-Cl-cAMP-treated cells exhibited a partial overlap with each other; the same set of down-regulated genes and different sets of up-regulated genes (except a few genes) between the two samples on the basis of $Z$ ratio. A scatter plot revealed a single type of down-regulation but a bifurcated type of up-regulation, confirming the result (Figure. 3). Representative genes differentially or coincidentally regulated are presented in Table 2 . These results indicated that two drugs shared some common genomic pathways leading to the down-regulation of certain genes, but used distinct pathways for most upregulated gene clusters involved in different categories

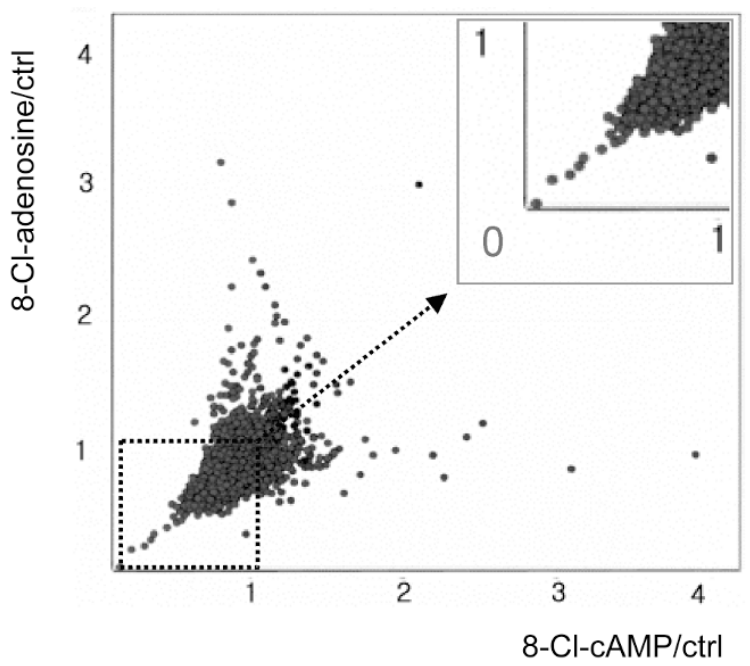

Figure 3. Scatter plot for comparison of expression profile between 8-Cladenosine- or 8-Cl-cAMP-treated SK-N-DZ cells. Expression profiles of 8-Cladenosine-treated versus 8-Cl-cAMP-treated cells are shown as bivariate scatter plot of 2,304 genes from the microarray. The values are corrected intensities relative to untreated control cells, representing levels of expression for the DNA elements of the microarrays. Scatter plot shows a bifurcated type of up-regulation indicating different sets of up-regulated genes and a single type of down-regulation indicating a same set of downregulated genes between two samples. The inset is a magnified drawing. of cellular processes. Based on the findings, it could be hypothesized that the anti-cancer activities of cAMP were due to direct modulation of PKA independent of 8$\mathrm{Cl}$-adenosine, or via its metabolite, 8-Cl-adenosine, which explains the striking overlaps between down-regulated genes by the two drugs, or a concerted action of the both pathways.

\section{Differential gene up-regulation by 8 -Cl-adenosine and 8-Cl-cAMP detected by microarray was verified by Western analysis}

To confirm the differential up-regulation of genes by 8$\mathrm{Cl}$-adenosine and 8-Cl-cAMP identified by microarray, Western blotting of two differentially regulated genes was performed to examine the direction of changes as well as the magnitude of altered expression (Figure. 4). P21WAF1/CIP1 plays a pivotal role in cell cycle arrest. The expression of the gene in SK-N-DZ cells was preferentially increased by 8 -Cl-adenosine treatment in agreement with the previous report (Carlson et al., 2001), but not by 8-Cl-cAMP. Insulin like growth factor binding protein (IGFBP) expression increased remarkably by $12 \mathrm{~h}$ of treatment with 8-Cl-cAMP, which decreased up to $\approx$ one fourth the level at $24 \mathrm{~h}$. By contrast, $8-\mathrm{Cl}-$ adenosine did not change IGFBP expression. Both results closely matched the microarray data (Table 1 ).

\section{Molecular profiling of anticancer effects of $8-\mathrm{Cl}$ adenosine and 8-Cl-cAMP on SK-N-DZ cells}

The anticancer activities of 8-Cl-adenosine and 8-ClcAMP have been well known in a variety of cancer cells, and phase I clinical studies have been performed against solid tumors with some evidence of clinical response (Halgren et al., 1998). Nevertheless, their precise molecular mechanisms of actions are not yet fully understood. To obtain a molecular portrait of these anticancer activities, we used a hierarchical clustering algorithm to group genes on the basis of similarity in their expression patterns (Eisen et al., 1998), and the data are presented in a matrix format (Figure. 5). Each row represents all of the hybridization results for a single DNA element of the array, and each column represents the expression levels for all genes in a single hybridization sample. The expression level of each gene is visualized in color, relative to its median expression level across all samples. Red represents an expression greater than the mean and green represents an expression less than the mean, and the intensity of the color denotes the degree of deviation from the mean. Black represents median expression level. Distinct samples representing similar gene patterns from control cells are aligned in adjacent rows. Included in this map are samples from untreated control and 8-Cl-adenosine- or 8Cl-cAMP-treated SK-N-DZ cells. Coordinately expressed genes were grouped into clusters, which we named on 
Table 2. Gene regulation profile in 8-Cl-adenosine- or 8-Cl-cAMP-treated SK-N-DZ cells

\begin{tabular}{|c|c|c|c|}
\hline \multicolumn{2}{|c|}{ Regulation profile and $Z$ ratio } & \multirow{2}{*}{ Gene product } & \multirow{2}{*}{ Function } \\
\hline 8-Cl-adenosine/control & 8-Cl-cAMP/control & & \\
\hline Up-regulated & Up-regulated & & \\
\hline 4.17 & 5.53 & Neurofilament triplet $L$ protein & Differentiation of nervous system, DCC-related protein \\
\hline 3.02 & 2.32 & Neogenin (chicken) homolog 1 & NK cells and $\mathrm{T}$ cells activation \\
\hline 2.29 & 2.80 & Natural killer cells protein 4 precursor & Cell cycle control, antigen presentation \\
\hline 2.10 & 3.40 & Human mRNA for proteasome subunit $z$ & \\
\hline Up-regulated & Down-regulated & & \\
\hline 7.82 & -0.44 & Homo sapiens (clone s153) mRNA fragment & Regulation of the colloidal osmotic pressure of blood \\
\hline 6.85 & -0.39 & H.sapiens mRNA for M130 antigen & Macrophage scavenger receptor \\
\hline 5.43 & -0.22 & Gap junction protein, beta 2 (connexin 26 ) & Human mammary differentiation, murine development \\
\hline 5.06 & -1.26 & Hexokinase 1 & Glycolysis \\
\hline Down-regulated & Up-regulated & & \\
\hline-0.79 & 6.14 & Vascular endothelial growth factor related protein (VRP) & Vascular development \\
\hline-0.43 & 5.59 & Alpha-2-HS-glycoprotein alpha and beta chain & Brain development, endocytosis \\
\hline-0.05 & 4.37 & E2F transcription factor $4, \mathrm{p} 107 / \mathrm{p} 130$ binding & Transcription factor \\
\hline-0.46 & 4.33 & Cyclin D2 & Promotion of cell cycle progression \\
\hline Down-regulated & Down-regulated & & \\
\hline-7.32 & -6.29 & Human mRNA for TGF-beta superfamily protein & Growth factor \\
\hline-6.20 & -4.60 & Human mRNA for stac, complete cds & Neuron-specific signal transduction \\
\hline-5.68 & -4.90 & Carbonic anhydrase II & Reversible hydratation of carbon dioxid \\
\hline-4.43 & -3.55 & H.sapiens mRNA for protein kinase, DYRK2 & Regulation of cellular growth and/or development \\
\hline
\end{tabular}


A

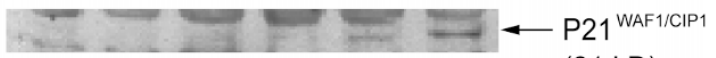

(21 kD)

B

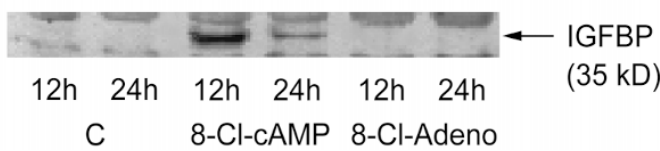

Figure 4. Expression of p21 WAF1/CIP1 $^{2}$ and IGFBP in 8-Cl-adenosine- or 8-ClCAMP-treated SK-N-DZ cells identified by Western blot vanalysis. Cells were treated with 8-Cl-adenosine or 8-Cl-cAMP for 12 or $24 \mathrm{~h}$. Untreated and treated cell lysates were subjected to Western blotting as described in Materials and Methods. C, untreated control; 8-Cl-cAMP, 8-Cl-cAMP-treated cells; 8-Cl-Adeno, 8-Cl-adenosine-treated cells.

the basis of the cellular process in which the component genes participate.

The clustergram revealed that $8-\mathrm{Cl}$-adenosine treatment up-regulated clusters of genes involved in differentiation and development, and down-regulated ones involved in proliferation and transformation, as compared to untreated control cells (Table 1, Figure. 5). The differentiation cluster was characterized by the prevalence of genes encoding developmental proteins (human LIM protein
MLP, connexin 26 and neogenin), genes encoding cytoskeleton (neurofilament triplet $L$ protein) and cell cycle proteins (p21 ${ }^{\mathrm{WAF} 1 / \mathrm{CIP} 1}$ and proteasome subunit $\mathrm{z}$ ). Some immune molecules were also up-regulated, including H.sapiens RFXAP, natural killer cells protein 4 and M130. LIM protein may be involved in specification and maintenance of differentiated phenotypical properties of some neurons (Thor et al., 1991) and an essential regulator of myogenic differentiation (Arber et al., 1994). Connexin 26 is expressed in normal human mammary epithelial cells but not in mammary tumor cell lines (Lee et al., 1992), and has an essential role during an early stage of murine development (Gabriel et al., 1998). Neogenin is a tumor suppressor gene DCCrelated protein, and believed to be involved in early differentiation of nervous system (Vielmetter et al., 1997). Neurofilament triplet $L$ protein is the component of neuronal cytoskeleton found in neurons of both the central and peripheral nervous systems (Carpenter and Wallace, 1996), and the up-regulation of its expression can be regarded as evidence of differentiation or reverse transformation of neuronal cells. $\mathrm{P} 21^{\mathrm{WAF} 1 / \mathrm{CIP} 1}$ is a cell cycle inhibitor acting by inhibiting cyclin/CDKs (Carlson et al., 2001; Draus et al., 2001; Lee et al.,

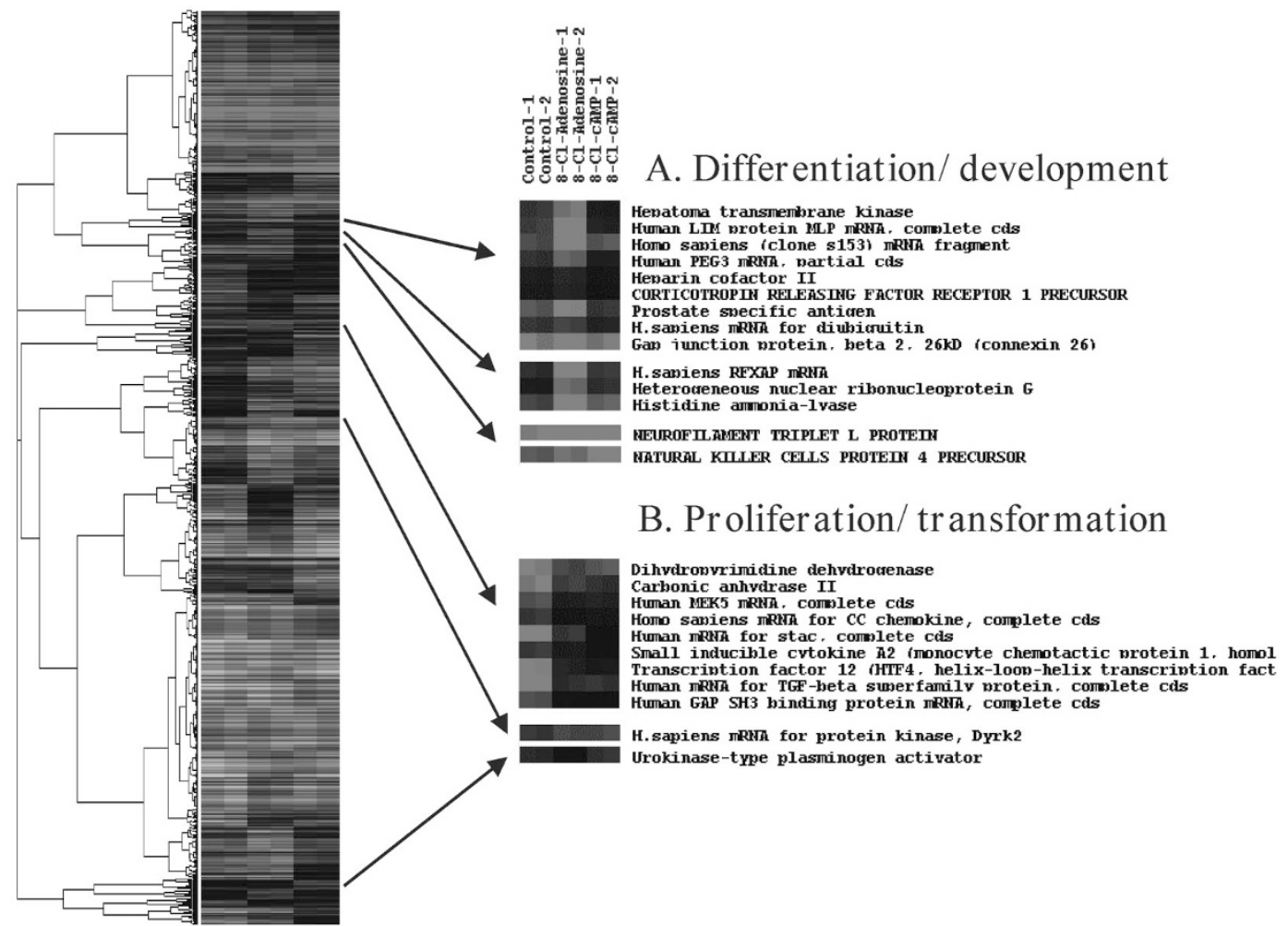

Figure 5. Molecular portrait of anticancer activities of 8-Cl-adenosine or 8-Cl-cAMP on SK-N-DZ cells. Cells were treated with 8-Cl-adenosine or 8-Cl-cAMP for $24 \mathrm{~h}$. Microarray data from untreated control and 8-Cl-adenosine or 8-Cl-cAMP-treated cells were combined and clustered. Cluster analysis was performed on Z-transformed microarray data by using two separate programs available as shareware from Michael Eisens lab. Each gene is represented by a single row of colored boxes; each experimental sample is represented by a single column. The entire clustered image is shown on the left. Full gene names are shown for coordinately expressed clusters containing genes involved in differentiation and development (A), and proliferation and transformation (B). These clusters also contain uncharacterized genes and genes not involved in these processes. 
2002). Proteasomes degrade protein-ubiquitin conjugates in an ATP-dependent reaction, and are involved in cell cycle control and in early steps of the immune response (Petit et al., 1997). RFXAP is critical to the expression of $\mathrm{MHC}$ class II genes and plays an ancillary role in the transcriptional control of MHC class I genes (Nagarajan et al., 2000). Natural killer cells protein 4 encodes a product common to the activation pathways of both natural killer (NK) cells and T cells (Dahl et al., 1992). M130 is a macrophage scavenger receptor, and not expressed in any cancer cells except mesothelioma where asbestos bound to the scavenger receptors (Frank et al., 1998). The coordinate up-regulation of the above genes most likely promotes differentiation and reverse transformation.

In the proliferation and transformation clusters, genes encoding proteins involved in proliferation or transformation-related signal transduction (transforming growth factor-b superfamily protein, stac, DYRK2 and LCR1 homolog), malignancy (urokinase-type plasminogen activator, neutrophil gelatinase-associated lipocalin), transcription (transcription factor 12, general transcription factor IIF/polypeptide 1), translation (DYRK2) and nucleic acid metabolism (dihydropyridine dehydrogenase) were preferentially down-regulated by both $8-\mathrm{Cl}$-adenosine and $8-\mathrm{Cl}$-cAMP with a similar magnitude of altered expression (Table 1, Figure. 5). Interestingly, the most profoundly down-regulated gene in SK-N-DZ cells by the two drugs was transforming growth factor- $\beta$ (TGF- $\beta$ ). TGF- $\beta$ has a multifunctional role in tumorigenesis, acting as a tumor suppressor as well as a tumor promoter by stimulating immunosuppression, angiogenesis and synthesis of extracellular matrix (Heldin et al., 1997). Further study is in need on the involvement of TGF- $\beta$ down-regulation in the up-regulation of some immune molecules [natural killer cells protein 4 precursor $(2.29$ fold by $8-\mathrm{Cl}$-adenosine, 2.80 fold by 8 -Cl-cAMP), RFXAP (3.96, 0.17)] and down-regulation of some extracellular matrix proteins [cartilage linking protein 1 (-3.08, -3.06), laminin B1 (-2.96, -2.30), collagen type V alpha $1(-2.55,-2.52)$, collagen type XV alpha $1(-2.50$, -1.39)] observed in the present experiment. Among the highly down-regulated molecules, stac is likely involved in neuron-specific signal transduction (Suzuki et al., 1996). DYRK2 is a member of the dual specificity tyrosine phosphorylated and regulated kinase group. A concerted action of DYRK2 and glycogen synthase kinase-3 regulates translation initiation factor elF2B, which is involved in switching on overall protein synthesis (Campbell and Proud, 2002). LCR1 is a Gprotein-coupled receptor, which likely influences neuronal function at the time after maturation of brain (Wong et al., 1996). Urokinase-type plasminogen activator forms part of an important enzymatic system that degraded the extracellular matrix in process of invasion and metastasis, thereby having a strong clinical value in predicting prognosis and survival of cancer patients (Schmitt et al., 2000; Nieto-Rodriquez et al., 2001). Neutrophil gelatinase-associated lipocalin appears to be induced in epithelial cells under special conditions such as malignancy and inflammation (Nielsen et al., 1996; Cowland and Borregaard, 1997). Dihydropyrimidine dehydrogenase (EC 1.3.1.2) is involved in uracil and thymine degradation, and the inhibition of the enzyme can greatly potentiate the therapeutic effectiveness of 5fluorouracil (Rosenbaum et al., 1997). A concomitant down-regulation of the above genes seemed to be of particular relevance to the anticancer activities of the two drugs. The suppressive effect of $8-\mathrm{Cl}$-adenosine on these gene clusters remarkably resembled that of $8-\mathrm{Cl}$ cAMP, indicating their use of distal common genomic pathways for the down-regulation of these genes. Furthermore, the altered expression profile generated by $8-\mathrm{Cl}$-adenosine or $8-\mathrm{Cl}$-cAMP treatment would reflect true intrinsic differences between the untreated and treated cells rather than variations arising from experimental artifacts.

In summary, we performed radioactive human cDNA microarray to elucidate genomic mechanisms of anticancer activities of $8-\mathrm{Cl}$-adenosine versus $8-\mathrm{Cl}-\mathrm{cAMP}$, which has been controversial for a long time. In the present study, the down-regulated genes by $8-\mathrm{Cl}$-adenosine treatment were closely mirrored in those by $8-\mathrm{Cl}$-cAMP. In contrast, the distinct clusters of genes were upregulated by the two drugs. Therefore, our data suggest that $8-\mathrm{Cl}$-adenosine and $8-\mathrm{Cl}$-cAMP use differential gene regulation mechanisms for their anticancer activities, however, sharing some common distal events with each other. Furthermore, we also suggest that the anti-cancer activities of 8-Cl-cAMP are derived from both direct modulation of PKA independent of its metabolite, 8-Cladenosine, and also via $8-\mathrm{Cl}$-adenosine which explains the striking overlaps among the down-regulated genes by the two drugs. Additionally, 8-Cl-adenosine specifically up-regulated expression of the differentiation and development clusters, and preferentially down-regulated the proliferation and transformation clusters, thereby providing a new level of understanding of the genomewide mechanism underlying its anticancer activity.

Finally, genome-wide expression profiling using human cDNA microarray has been proven to be an efficient technology to evaluate the genomic mechanism of closely related cancer therapeutics, such as $8-\mathrm{Cl}-$ adenosine and 8-Cl-cAMP, and facilitate the development of new chemotherapeutic combinations based on the dynamic molecular actions of drugs.

\section{Acknowledgments}

This work was supported by Korean Health $21 \mathrm{R}$ and $\mathrm{D}$ Project, Ministry of Health and Welfare (Grant\# HMP- 
00-GN-01-002) and by National Nuclear $R$ and $D$ program from the Korean Ministry of Science and Technology. We especially thanks to Drs. Su-Jae Lee and Yun-Sil Lee in Laboratory of Radiation Effect, Korea Cancer Center Hospital, Seoul, Korea for their kind academic advises.

\section{References}

Ally S, Tortora G, Clair T, Grieco D, Merlo G, Katsaros D, Ogreid D, Doskeland SO, Jahnsen T, Cho-Chung YS. Selective modulation of protein kinase isozymes by the site-selective analog 8-chloroadenosine 3',5'-cyclic monophosphate provides a biological means for control of human colon cancer cell growth. Proc Natl Acad Sci U S A 1988;85:6319-22

Arber S, Halder G, Caroni P. Muscle LIM protein, a novel essential regulator of myogenesis, promotes myogenic differentiation. Cell 1994;79:221-31

Campbell LE, Proud CG. Differing substrate specificities of members of the DYRK family of arginine-directed protein kinases. FEBS Letters 2002;510:31-36

Carlson CC, Burnham LL, Shanks RA, Dransfield DT. 8-Cladenosine induces differentiation in LS174T cells. Dig Dis Sci 2001;46:757-64

Carpenter DA, Wallace Ip. Neurofilament triplet protein interactions: evidence for the preferred formation of NF-Lcontaining dimers and a putative function for the end domains. J Cell Sci 1996;109:2493-98

Cho-Chung YS. Site-selective 8-chloro-cyclic adenosine 3',5'monophosphate as a biologic modulator of cancer: restoration of normal control mechanisms. J Natl Cancer Inst 1989;81:982-87

Cho-Chung YS. Role of cyclic AMP receptor proteins in growth, differentiation, and suppression of malignancy: new approaches to therapy. Cancer Res 1990;50:7093-100

Cho-Chung YS, Pepe S, Clair T, Budillon A, Nesterova, M. cAMP-dependent protein kinase: role in normal and malignant growth. Crit Rev Oncol Hematol 1995;21:33-61

Cho YS, Park YG, Lee YN, Kim MK, Bates S, Tan L, ChoChung YS. Extracellular protein kinase $A$ as a cancer biomarker: its expression by tumor cells and reversal by a myristate-lacking Calpha and RIlbeta subunit overexpression. Proc Natl Acad Sci USA 2000;97:835-40

Ciardiello F, Tortora G, Kim N, Clair T, Ally S, Salomon DS, Cho-Chung YS. 8-Chloro-cAMP inhibits transforming growth factor alpha transformation of mammary epithelial cells by restoration of the normal mRNA patterns for cAMPdependent protein kinase regulatory subunit isoforms which show disruption upon transformation. J Biol Chem 1990;265:1016-20

Cowland JB, Borregaard N. Molecular characterization and pattern of tissue expression of the gene for neutrophil gelatinase-associated lipocalin from humans. Genomics 1997; $45: 17-23$
Cummings J, Langdon SP, Ritchie AA, Burns DJ, Mackay J, Stockman P, Leonard RC, Miller WR. Pharmacokinetics, metabolism and tumour disposition of 8-chloroadenosine $3^{\prime}, 5^{\prime}$ monophosphate in breast cancer patients and xenograft bearing mice. Ann Oncol 1996;7: 291-96

Dahl CA, Schall RP, He HL, Cairns JS. Identification of a novel gene expressed in activated natural killer cells and T cells. J Immunol 1992;148:597-603

DeRisi J, Penland L, Brown PO, Bittner ML, Meltzer PS, Ray M, Chen Y, Su YA, Trent JM. Use of a cDNA microarray to analyse gene expression patterns in human cancer. Nat Genet 1996:14:457-60

Draus JM, Elliott MJ, Atienza C Jr, Stilwell A, Wong SL, Dong $\mathrm{Y}$, Yang $\mathrm{H}$, McMasters KM. p53 gene transfer does not enhance E2F-1-mediated apoptosis human colon cancer cells. Exp Mol Med 2001;33:209-19

Duggan DJ, Bittner $\mathrm{M}$, Chen $\mathrm{Y}$, Meltzer $\mathrm{P}$, Trent JM. Expression profiling using cDNA microarrays. Nat Genet 1999;21:10-14

Eisen MB, Spellman PT, Brown PO, Botstein D. Cluster analysis and display of genome-wide expression patterns. Proc Natl Acad Sci USA 1998;95:14863-68

Frank S, Specht B-U, Farthmann EH, Hirsch T. Identification of genes involved in human mesothelial cancer progression using a modified differential display technique. Cancer Lett 1998; $123: 7-14$

Gabriel HD, Jung D, Butzler C, Temme A, Traub O, Winterhager E, Willecke K. Transplacental uptake of glucose is decreased in embryonic lethal connexin 26-deficient mice. J Cell Biol 1998;140:1453-61

Halgren RG, Traynor AE, Pillay S, Zell JL, Heller KF, Krett NL, Rosen ST. 8-Cl-cAMP cytotoxicity in both steroid sensitive and insensitive multiple myeloma cell lines is mediated by $8-\mathrm{Cl}$ adenosine. Blood 1998;92:2893-98

Heldin C-H, Miyazono K, Dijke P. TGF-beta signalling from cell membrane to nucleus through SMD proteins. Nature 1997;390:465-71

Konu O, Kane JK, Barrett T, Vawter MP, Chang R, Ma JZ, Donovan DM, Sharp B, Becker KG, Li MD. Region-specific transcriptional response to chronic nicotine in rat brain. Brain Res 2001;909:194-203

Lange-Carter CA, Vuillequez JJ, Malkinson AM. 8Chloroadenosine mediates 8-chloro-cyclic AMP-induced down-regulation of cyclic AMP-dependent protein kinase in normal and neoplastic mouse lung epithelial cells by a cyclic AMP-independent mechanism. Cancer Res1993;53:393-400

Langeveld $\mathrm{CH}$, Jongenelen CA, Theeuwes JW, Baak JP, Heimans JJ, Stoof JC, Peters GJ. The antiproliferative effect of 8-chloro-adenosine, an active metabolite of 8-chloro-cyclic adenosine monophosphate, and disturbances in nucleic acid synthesis and cell cycle kinetics. Biochem Pharmacol 1997;53:141-48

Lee JK, Jung JC, Chun JS, Kang SS, Bang OS. Expression of p21WAF1 is dependent on the activation of ERK during vitamin E-succinate-induced monocytic differentiation. Mol 
Cells 2002;13:125-29

Lee SW, Tomasette C, Paul D, Keyomarsi K, Sager R. Transcriptional downregulation of gap junction proteins blocks junctional communication in human mammary tumor cell lines. J Cell Biol 1992;118:1213-21

Miller WR, Hulme MJ, Bartlett JM, MacCallium J, Dison JM. Changes in messenger RNA expression of protein kinase $A$ regulatory subunit alpha in breast cancer patients treated with tamoxifen. Clin Cancer Res 1997;3:2399-404

Miller WR, Hulme MJ, Cho-Chung YS, Elton RA. Types of cyclic AMP binding proteins in human breast cancers. Eur. J. Cancer 1993a;29:989-91

Miller WR, Watson DMA, Jack W, Chetty U, Elton RA. Tumour cyclic AMP binding proteins: an independent prognostic factor for disease recurrence and survival in breast cancer. Breast Cancer Res Treat 1993b;26:89-94

Nagarajan UM, Peijnenburg A, Gobin SJP, Boss JM, Elsen PJ. Novel mutations within the RFX-B gene and partial rescue of $\mathrm{MHC}$ and related genes through exogenous class II transactivator in RFX-B-deficient cells. J Immunol 2000; 164:3666-74

Nielsen BS, Borregaard N, Bundgaard JR, Timshel S, Sehested M, Kjeldsen L. Induction of NGAL synthesis in epithelial cells of human colorectal neoplasia and inflammatory bowel diseases. Gut 1996;38:414-20

Nieto-Rodriquez A, Hernandez-Pando R, Kershenobich D, Rodriquez-Fragoso L. Expression of urokinase-type plasminogen activator in an experimental model of hepatocarcinoma. Toxicology 2001;161:13-23

Noguchi K, Murata T, Cho-Chung YS. 8-chloroadenosine 3',5'monophosphate (8-Cl-cAMP) selectively eliminates protein kinase A type I to induce growth inhibition in c-ras-transformed fibroblasts. Eur J Cancer 1998;34:1260-67

Petit F, Jarrousse A-S, Dahlmanin B, Sobek A, Hendil KB, Buri J, Briand Y, Schmid H-P. Involvement of proteasomal subunits zeta and iota in RNA degradation. Biochem $J$ 1997;326:93-98

Rohlff C, Clair T, Cho-Chung YS. 8-Cl-cAMP induces truncation and down-regulation of the $\mathrm{RI}$ alpha subunit and up-regulation of the RII beta subunit of CAMP-dependent protein kinase leading to type II holoenzyme-dependent growth inhibition and differentiation of HL-60 leukemia cells. J Biol Chem 1993; 268:5774-82

Rosenbaum K, Schaffrath B, Hagen WR, Jahnke K, Gonzalez FJ, Cook PF, Schnackerz KD. Purification, characterization, and kinetics of porcine recombinant dihydropyrimidine dehydrogenase. Prot Expression and Purification 1997;10:185-91

Schena M, Shalon D, Davis RW, Brown PO. Quantitative monitoring of gene expression patterns with a complementary DNA microarray. Science 1995;270:467-70

Schmitt M, Wilhelm OG, Reuning U, Kruger A, Harbeck N, Lengyel E., Graeff H, Gansbacher B, Kessler H, Burgle M, Sturzebecher J, Sperl S, Magdolen V. The urokinase plasminogen activator system as a novel target for tumour therapy. Fibrinolysis and Proteolysis 2000;14:114-32

Simpson BJB, Ramage AD, Hulme MJ, Burns DJ, Katsaros D, Langdon SP, Miller WR. Cyclic adenosine 3,5monophosphate-binding proteins in human ovarian cancer: correlations with clinicopathological features. Clin Cancer Res 1996;2:201-6

Srivastava RK, Srivastava AR, Seth P, Agrawal S, Cho-Chung YS. Growth arrest and induction of apoptosis in breast cancer cells by antisense depletion of protein kinase A-R1 alpha subunit: p53-independent mechanism of action. Mol Cell Biochem 1999;195:25-36

Suzuki H, Kawai J, Taga C, Yaoi T, Hara A, Hirose K, Hayashizaki Y, Watanabe S. Stac, a novel neuron-specific protein with cystein-rich and $\mathrm{SH} 3$ domains. Biochem Biophys Res Com 1996;229:902-9

Tanaka TS, Jaradat SA, Lim M, Kargul GJ, Wang X, Grahovac MJ, Pantano S, Sano Y, Piao Y, Nagaraja R. Genome-wide expression profiling of mid-gestation placenta and embryo using a 15,000 mouse developmental cDNA microarray. Proc Natl Acad Sci USA 2000;97:9127-32

Taylor SS, Buechler JA, Yonemoto W. cAMP-dependent protein kinase: framework for a diverse family of regulatory enzymes. Annu Rev Biochem 1990;59:971-1005

Thor S, Ericson J, Brannstrom T, Edlund T. The homeodomain LIM protein Isl-1 is expressed in subsets of neurons and endocrine cells in the adult rat. Neuron 1991;7:881-89

Vawter MP, Barrett T, Cheadle C, Sokolov BP, Wood WH 3rd, Donovan DM, Webster M, Freed WJ, Becker KG. Application of cDNA microarrays to examine gene expression differences in schizophrenia. Brain Res Bull 2001;55:641-50

Vielmetter J, Chen X-N, Miskevich F, Lane RP, Yamakawa K, Korenberg JR, Dreyer WJ. Molecular characterization of human neogenin, a DCC-related protein, and the mapping of its gene (NEO1) to chromosomal position 15q22.3-q23. Genomics 1997;41:414-21

Wong ML, Xin WW, Duman RS. Rat LCR1: cloning and cellular distribution of a putative chemokine receptor in brain. Mol Psychiatry 1996;1:133-40

Yin Y, Allen PD, Jia L, Kelsey SM, Newland AC. 8-Cladenosine mediated cytotoxicity and sensitization of $\mathrm{T}$ lymphoblastic leukemia cells to TNFalpha-induced apoptosis is via inactivation of NF-kappaB. Leuk Res 2001;25:423-31 